\title{
Identification of acoustic fields in aqueous biomass solutions of banana waste pretreated by power ultrasound
}

\author{
H. A. Villa-Vélez ${ }^{1,2}$ - M. L. Cornelio ${ }^{3}$ J. L. G. Corrêa ${ }^{4} \cdot$ J. Telis-Romero $^{2}$
}

Received: 2 October 2016 / Revised: 23 February 2017 / Accepted: 19 March 2017 /Published online: 1 April 2017

(C) Springer-Verlag Berlin Heidelberg 2017

\begin{abstract}
High-intensity ultrasound is a technology used to improve the performance of processes in the chemical, pharmaceutical, biomass pretreatment, and food industries. However, few studies were described in the literature to comprehend the acoustic wave propagation in the material and their efficiency in the process. Thus, this study aims to determine the acoustic fields of aqueous biomass solutions from flower stalk banana using the calorimetric method and a determined sonotrode position. These tests were conducted at temperatures from 0 to $60{ }^{\circ} \mathrm{C}$ and ultrasound power from 120,160 , to $320 \mathrm{~W}$. Also, the specific heat capacity and density of the solution were determined experimentally as a function of the solution concentration $(0.040$ to $0.100 \mathrm{~g}$ biomass $\left.\mathrm{mL}^{-1}\right), \mathrm{pH}(3,5$, and 7$)$, and temperature. The position of the thermocouple was maintained at $1 \mathrm{~cm}$ from the sonotrode, and the ultrasound frequency was $24 \mathrm{kHz}$. The methods and results presented in this study can be used to reproduce acoustic field calculations in aqueous biomass solutions, aiming the construction of acoustic processor systems.
\end{abstract}

H. A. Villa-Vélez

harvey.villa@ufma.br

1 Coordenação do Curso de Engenharia Química, Centro de Ciência Exatas e Tecnologias, Universidade Federal do Maranhão, Avenida dos Portugueses 1966, Bairro Bacanga, São Luís, MA 65080-805, Brazil

2 Departamento de Engenharia e Tecnologia de Alimentos, Universidade Estadual Paulista, São José do Rio Preto, SP, Brazil

3 Departamento de Física, Universidade Estadual Paulista, São José do Rio Preto, SP, Brazil

4 Departamento de Ciência dos Alimentos, Universidade Federal de Lavras, Lavras, MG, Brazil
Keywords Acoustic intensity $\cdot$ Density $\cdot$ Flower stalk banana $\cdot$ Power ultrasound $\cdot$ Specific heat capacity $\cdot$ Stepwise regression

\section{Introduction}

Within the last few decades, lignocellulosic biomass has been reported as a raw material for biotechnological processes in the bioenergy industry [1]. Lignocellulosic biomass is cheaper than first-generation food-based feedstock, since its use does not compete with food and feed supplies [2] and it is more friendly to the environment [3]. Flower stalk banana is a raw material with high content of cellulose $[2,4]$ that could be converted to fermentable sugar through enzymatic hydrolysis processes with mass performance and net energy values that are comparable with those of lignocellulosic materials $[5,6]$.

The processing of lignocellulosic biomass has been reported from literature using physical [4], physicochemical [7], chemical $[8,9]$, and electrical [10] methods. However, most of these studies show the influence of each method on the production of fermentable sugar instead of the process efficiency and its physical effect.

The use of physical methods that employ mechanical acoustic waves in a liquid media by using ultrasound technology promotes cavitation, which occurs through the spontaneous formation, growth, and collapse of millions of microscopic bubbles. This phenomenon produces high temperatures and pressures that last for microseconds and produces a hotspot effect in the cold liquid [11]. These high cooling rates prevent the organization and crystallization of the precipitated products, which results in mostly amorphous particles $[12,13]$. The effects of high-intensity ultrasound depend on many variables, including medium properties (viscosity, surface tension, the composition and concentration of the solution, and 
the presence of solid particles) $[14,15]$ and operation parameters (pressure and temperature, ultrasound power and frequency, and the size and geometry of the treatment vessel) [16]. Consequently, it becomes difficult to compare the data. However, some advantages have been reported regarding the use of ultrasound. Cavitation could improve the chemical reactions [11] and mass transfer [15] and has been reported as an alternative for potentializing the production of fermentable sugar during biomass pretreatment. For example, highintensity ultrasound has been used to pretreat Areca nut husk, bon bogori, and moj [17] wastes in India and pulp mill waste [18] and dry maize milling [19] wastes to increase the glucose contents of the wastes, which resulted in greater biofuel yields.

By pretreating organic matter in solution using different ultrasonic power levels, Jiang et al. [20] demonstrated that the effects of ultrasound on the biomass are similar when the biomass is treated using low-intensity power over a long period or with high-intensity power over a short period. Other studies have indicated that combinations of high-intensity ultrasound and chemical methods can increase the efficiency of biomass pretreatment [18, 21-25].

Although the application of high-intensity ultrasound for biomass pretreatment has been reported, studies regarding the influences, spreading, and absorption of the acoustic waves in the biomass have not been conducted. Measurements of the acoustic power that is generated by an ultrasound source and the power that is absorbed in a volume of liquid under cavitation conditions have become urgent and important acoustic problems. These problems have only recently been solved because these properties are related to the characteristics of the material through which the acoustic energy propagates $[14,24]$. The following techniques have been used to quantify the energy efficiency in liquid media: calorimetric [26], sonochemiluminescence [27], electrical [28], and acoustic mapping methods $[29,30]$. The calorimetric method is considered as one of the best techniques because it is a very simple and its results can easily be compared with those of input power. In these measurements, the calorimetric energy may be estimated as a function of position in the liquid media $[26,31]$. However, the calorimetric method presents several problems when the experimental conditions (initial temperature of experimentation, position of the sonotrode, precision of the sensors, characteristics of the material, etc.) are not controlled. To overcome this problem, the classification of the electrical input energy into several energy terms, such as the absorption, dissipation, transducer heating, and heat loss to the surroundings, has been suggested to normalize and quantify the input power of the sonotrode and/or sonoreactor in the system [26, 32].

Based on these arguments, this work aims to determine the acoustic fields in aqueous solutions of biomass from banana waste (flower stalk) by the calorimetric method. For this, experimental correlations of the specific heat capacity and density of the solution by using differential scanning calorimetric and pycnometric methods were realized.

\section{Material and methods}

\subsection{Raw materials}

Banana flower stalks (Musa acuminata AAA cv. Dwarf Cavendish) were acquired from local farmers of the industry Banatech (Guapiaçu, São Paulo State, Brazil) and were stored at $15^{\circ} \mathrm{C}$ before use.

\subsection{Sample preparation}

The flower stalks were washed with water to remove foreign particles. Next, the stalks were cut longitudinally (in the direction of the fibers) and dried at $40{ }^{\circ} \mathrm{C}$ at an air velocity of $3.0 \mathrm{~m} \mathrm{~s}^{-1}$, until obtaining a product with a moisture content of $9.2 \mathrm{~g} \mathrm{H}_{2} \mathrm{O}$ per kilogram of dry matter. Next, the dried flower stalks were ground in a knife mill (model MA380, Marconi, Brazil) to obtain particle sizes of 50 to $200 \mu \mathrm{m}$.

Aqueous biomass solutions with concentrations of 0.000 , $0.040,0.060,0.080$, and $0.100 \mathrm{~g} \mathrm{~mL}^{-1}$ were prepared by mixing the powdered flower from the banana stalk with deionized water. Due to the high water absorption capacity and swelling of the flower stalk powder, previous assays indicated that the maximum possible biomass concentration was $0.100 \mathrm{~g} \mathrm{~mL}^{-1}$. Each solution, with a volume of $1.8 \mathrm{~L}$, was acidified to $\mathrm{pH} 3.0,4.0,5.0,6.0$, or 7.0 by using a $0.001 \%$ $\mathrm{H}_{2} \mathrm{SO}_{4}$ solution and monitored until stabilization. The $\mathrm{pH}$ measurements were made using a $\mathrm{pH}$ meter (model mPA210, MS Tecnopon, Brazil).

\subsection{Density determination, $\rho$}

The $\rho$ of the biomass solution was determined by weighting a standard $25-\mathrm{mL}$ volumetric glass pycnometer (Brand, Wertheim, Germany) on a precision scale $(0.0001 \mathrm{~g})$. The pycnometer was equipped with a cap and thermometer $( \pm$ $0.1^{\circ} \mathrm{C}$ ) at $0,10,20,30,40,50$, and $60^{\circ} \mathrm{C}$ and was previously calibrated using distilled water for each temperature (AOAC, method 985.19) [33]. The temperature was maintained using a thermostatic bath (model MA-159, Marconi, Brazil).

\subsection{Experimental conditions of high-intensity ultrasound}

The acoustic fields of the aqueous biomass solutions were determined using an ultrasonic processor (model UP400S, Hielscher Ultrasonics $\mathrm{GmbH}$, Germany) with a titanium sonotrode, with a tip diameter of $22 \mathrm{~mm}$ (model H40, Hielscher Ultrasonics GmbH, Germany). This ultrasonic processor operated at a frequency of $24 \mathrm{kHz}$ and with a maximum 
Fig. 1 Experimental setup for determining the acoustic fields using the calorimetric method

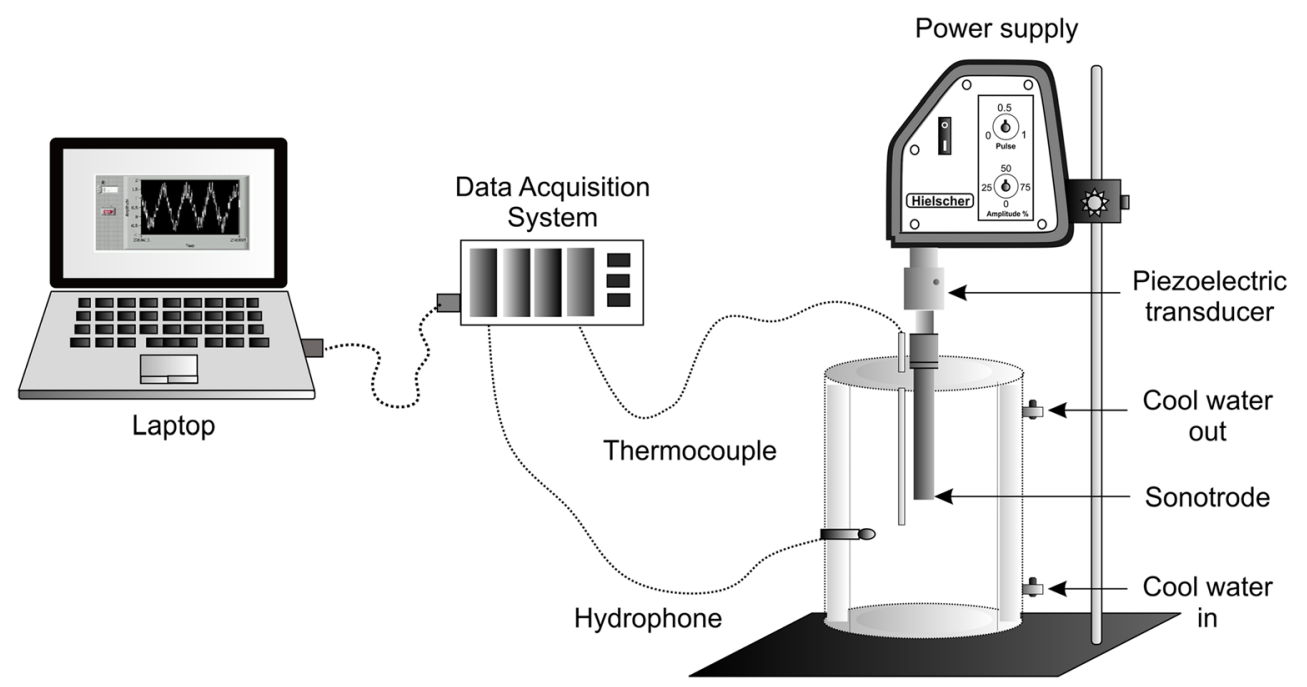

this method and by measuring the increases in temperature over the first $210 \mathrm{~s}$ [24]. The increase in temperature was recorded using a type $\mathrm{J}$ thermocouple connected to an acquisition data system that was provided with the software (LabVIEW 2010, National Instruments $®$, USA). The thermocouple position was held constant at $1.0 \mathrm{~cm}$ from the sonotrode. This position was determined previously based on maximum acoustic intensity measurements that were obtained using a hydrophone model TC4014 (RESON A/S, Slangerup, Denmark) that was adapted to the acquisition system, as indicated in Fig. 1.

Thus, the actual energy of the power ultrasound was determined using Eq. (1):

$P=m c_{p} \frac{d T}{d t}$

where $P$ is the energy that the power ultrasound propagated in the aqueous biomass solution at a determined position (W), $m$ is the mass of the aqueous biomass solution $(\mathrm{kg})$ calculated from its experimental density $\left(\rho, \mathrm{kg} \mathrm{m}^{-3}\right), c_{p}$ is the specific heat capacity of the aqueous biomass solution that was determined experimentally using differential scanning calorimetry $\left(\mathrm{kJ} \mathrm{kg}^{-1}{ }^{\circ} \mathrm{C}^{-1}\right)$, and $d T / d t$ is the temperature gradient with the

Table 1 Fitting model results of the densities of the aqueous solutions containing biomass according to the stepwise regression method

\begin{tabular}{lllll}
\hline Coefficient & Value & $p(<0.05)$ & $R_{\text {adj }}^{2}$ & MRE (\%) \\
\hline Intercept & 1001.2 & - & 0.977 & 0.174 \\
$x$ & 465.7 & $2.679 \times 10^{-22}$ & & \\
$\mathrm{pH}$ & -0.929 & $1.363 \times 10^{-4}$ & & \\
$\mathrm{~T}^{2}$ & $-3.774 \times 10^{-3}$ & $1.787 \times 10^{-62}$ & & \\
$x \cdot \mathrm{pH}$ & -34.364 & 0.037 & & \\
$\mathrm{pH}^{2} x$ & 3.759 & 0.020 & & \\
\hline
\end{tabular}

Fig. 2 Experimental ( $\mathrm{pH}=3$ (asterisk), $\mathrm{pH}=4$ (diamond), $\mathrm{pH}=5$ (plus sign), $\mathrm{pH}=6$ (triangle), and $\mathrm{pH}=7$ (circle)) and calculated (mesh (square) densities of the aqueous solutions of biomass using the correlated model as a function of the temperature $(\mathrm{T})$ and biomass concentration $(x)$ 
Fig. 3 Residual analysis between the experimental and calculated data for the density of the aqueous solutions containing biomass
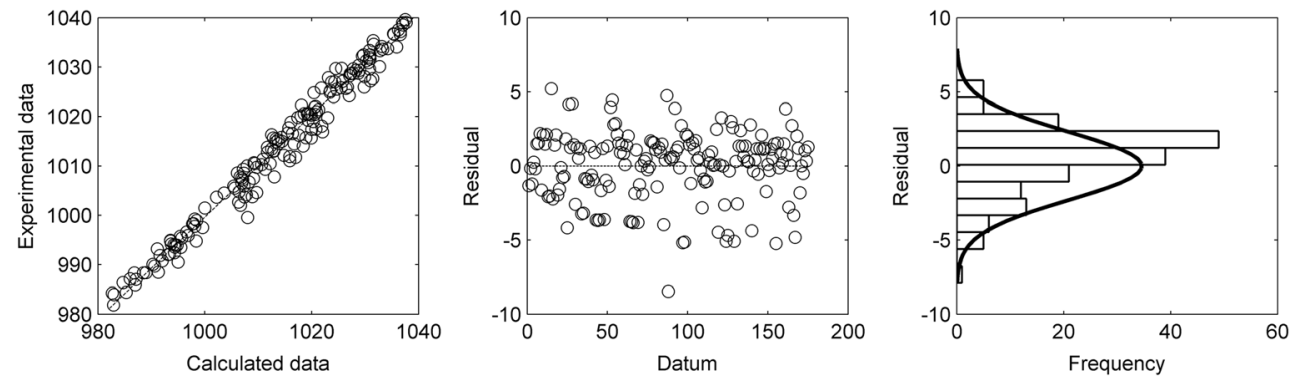

amount of time that the aqueous biomass solution was submitted to the nominal input power levels $\left({ }^{\circ} \mathrm{C} \mathrm{s}{ }^{-1}\right)$. Additionally, if this power (W) is dissipated into the system from a probe tip with an area of $A\left(\mathrm{~cm}^{2}\right)$, then the acoustic intensity $\left(I, \mathrm{~W} \mathrm{~cm}{ }^{-2}\right)$ produced by the ultrasound source is given by Eq. (2) [34]:

$I=\frac{P}{A}$

\subsection{Mathematical and statistical analyses}

The mathematical and statistical analyses were carried out using the functions from the computation software Matlab® version 7.1 (The MathWorks Inc., Natick, MA, USA). The theoretical and empirical models were fit using the "nlinfit" non-linear regression function considering the robust fitting option. Moreover, when the mathematical modeling requires selecting a model with the best combination from the
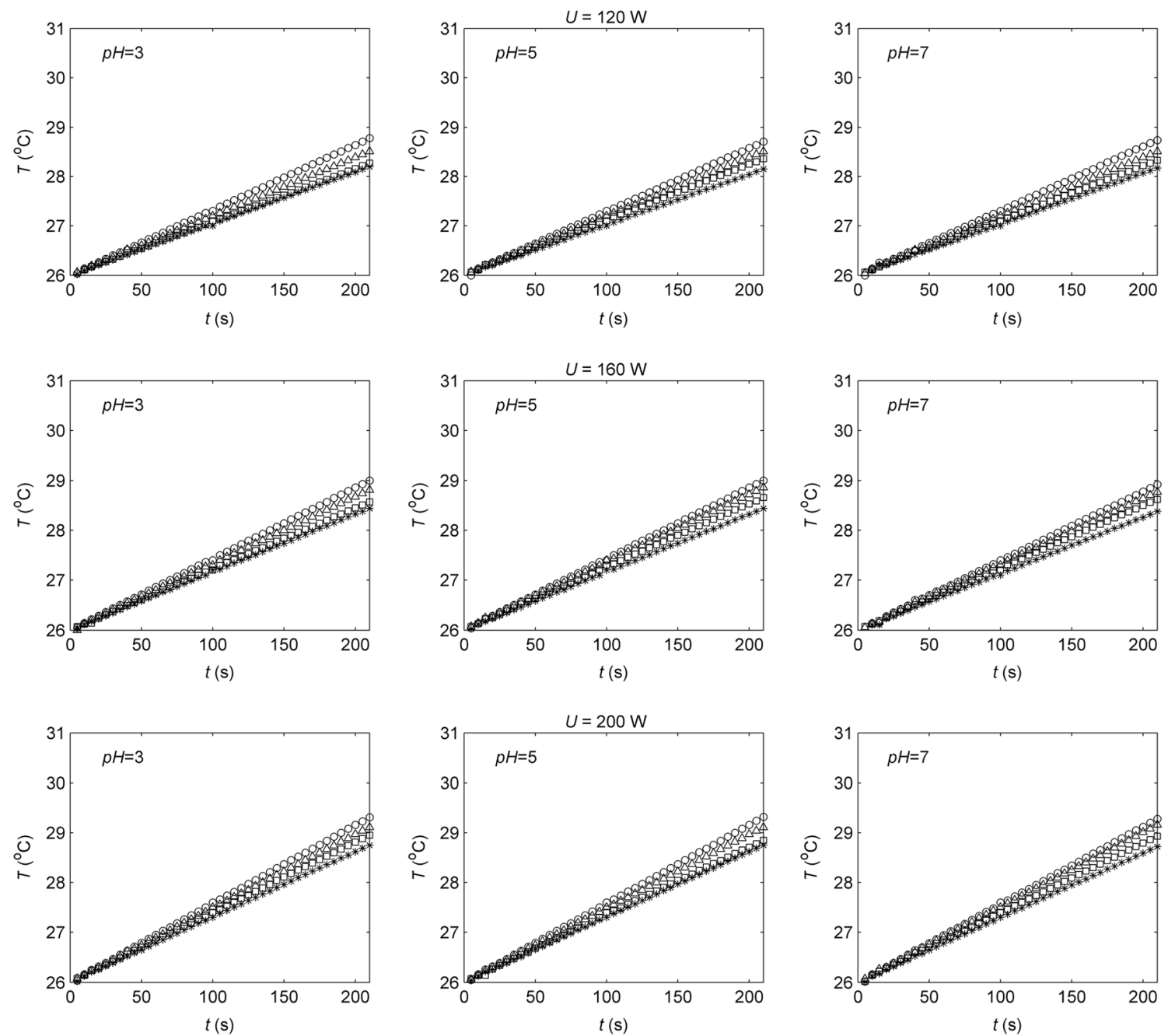

Fig. 4 Experimental temperature rates between 0 and $210 \mathrm{~s}$ of the aqueous solutions containing biomass at concentrations of $0.040 \mathrm{~g} / \mathrm{mL}$ (circle), $0.060 \mathrm{~g} / \mathrm{mL}$ (triangle), $0.080 \mathrm{~g} / \mathrm{mL}$ (square), and $0.100 \mathrm{~g} / \mathrm{mL}$

(asterisk) and $\mathrm{pH}$ values of 3, 5, and 7 when subjected to ultrasounds with nominal powers of $120,160,200,240,280$, and $320 \mathrm{~W}$ 

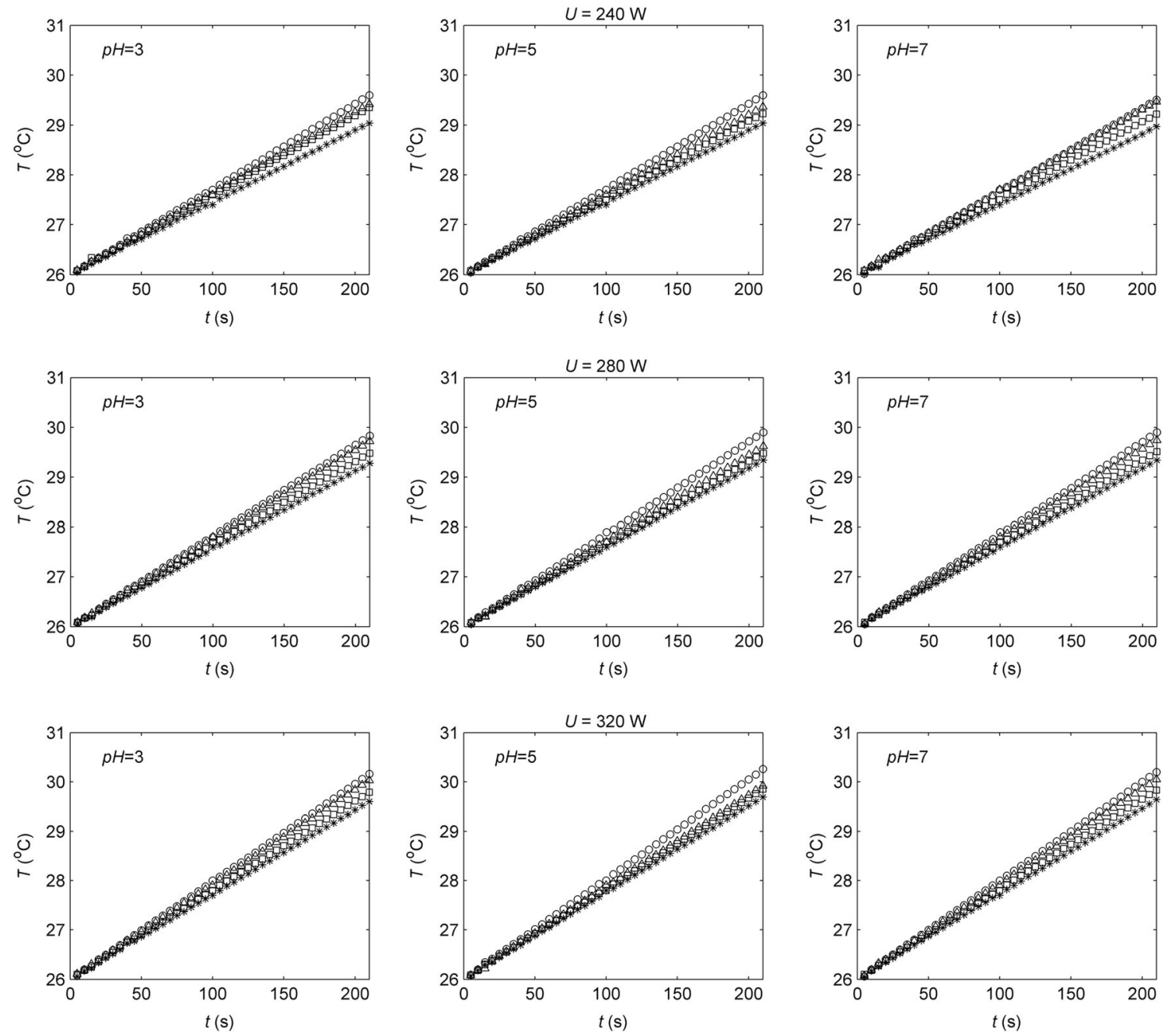

Fig. 4 continued.

experimental factors, the stepwise regression method is used from the "stepwisefit" function by adding or deleting the model terms that are evaluated from a significance test $(p<0.05)$ [35]. Thus, the model established by a stepwise procedure comprises a set of predictors that have important effects on the dependent variables and that best explain the response according to the interactions that are considered [36, 37]. Finally, once the best fitting models were established, residual analyses were carried out using the "lillietest" function, which determine the normal distribution with $\alpha=0.05$.

The adjusted coefficient of determination $\left(R_{\text {adj }}^{2}\right)($ Eq. (3)) and the mean relative error (MRE) (Eq. (4)) were used to evaluate the goodness of fit and accuracy of the estimation, respectively. A model with a value for MRE below $10 \%$ is considered to have good accuracy [38].

$R_{\text {adj }}^{2}=1-\left(1-R^{2}\right) \frac{n-1}{n-m}$

$\mathrm{MRE}=\frac{100}{n} \sum_{i=1}^{n} \frac{\left|Y-Y^{*}\right|}{Y}$ where $Y$ is the experimental data, $Y^{*}$ is the calculated data from the regression, $m$ is the number of parameters in the model, $n$ is the number of experimental data points used in the regression analysis and $R^{2}$ is the coefficient of determination.

\section{Results and discussion}

\subsection{Density and mathematical modeling}

Figure 2 shows the relationships between density and the biomass concentration and temperature, which were expected. Because the biomass itself presents a higher density, increasing the biomass concentration results in a greater increase in the solution. Moreover, as the temperature increases, the volume occupied by the molecules becomes larger and the density decreases [39]. There was no statistical influence of $\mathrm{pH}$.

On the other hand, the experimental values of $\rho$ were represented by the biomass concentration, temperature, and $\mathrm{pH}$ in a simple model by using the stepwise regression method. The 
Table 2 The regression of the linear model at nominal electrical power, biomass concentrations, and $\mathrm{pH}$

\begin{tabular}{|c|c|c|c|c|c|c|c|c|c|c|c|c|c|}
\hline \multirow[t]{2}{*}{$U$} & \multirow[t]{2}{*}{ Parameter } & \multicolumn{4}{|l|}{$\begin{array}{l}\mathrm{pH}=3 \\
x\end{array}$} & \multicolumn{4}{|l|}{$\begin{array}{l}\mathrm{pH}=5 \\
x\end{array}$} & \multicolumn{4}{|l|}{$\begin{array}{l}\mathrm{pH}=7 \\
x\end{array}$} \\
\hline & & 0.040 & 0.060 & 0.080 & 0.100 & 0.040 & 0.060 & 0.080 & 0.100 & 0.040 & 0.060 & 0.080 & 0.100 \\
\hline \multirow[t]{4}{*}{120} & $d T / d t\left(\times 10^{-2}\right)$ & 1.326 & 1.191 & 1.083 & 1.050 & 1.293 & 1.192 & 1.121 & 1.026 & 1.308 & 1.192 & 1.105 & 1.036 \\
\hline & $c$ & 25.993 & 26.007 & 25.997 & 25.995 & 25.995 & 26.005 & 26.003 & 25.994 & 25.997 & 26.004 & 26.004 & 25.998 \\
\hline & $R_{\text {adj }}^{2}$ & 0.999 & 0.999 & 0.999 & 0.999 & 0.999 & 0.999 & 0.999 & 0.999 & 0.999 & 0.999 & 0.999 & 0.999 \\
\hline & $\operatorname{MRE}(\%)$ & 0.016 & 0.012 & 0.019 & 0.017 & 0.018 & 0.008 & 0.015 & 0.020 & 0.021 & 0.012 & 0.014 & 0.021 \\
\hline \multirow[t]{4}{*}{160} & $d T / d t\left(\times 10^{-2}\right)$ & 1.431 & 1.341 & 1.227 & 1.163 & 1.431 & 1.358 & 1.262 & 1.163 & 1.397 & 1.323 & 1.248 & 1.139 \\
\hline & $c$ & 25.997 & 25.992 & 25.996 & 26.000 & 25.996 & 26.006 & 26.006 & 25.999 & 25.991 & 25.997 & 25.999 & 25.988 \\
\hline & $R_{\text {adj }}^{2}$ & 0.999 & 0.999 & 0.999 & 0.999 & 0.999 & 0.999 & 0.999 & 0.999 & 0.999 & 0.999 & 0.999 & 0.999 \\
\hline & $\operatorname{MRE}(\%)$ & 0.013 & 0.021 & 0.016 & 0.014 & 0.015 & 0.017 & 0.017 & 0.015 & 0.030 & 0.016 & 0.013 & 0.032 \\
\hline \multirow[t]{4}{*}{200} & $d T / d t\left(\times 10^{-2}\right)$ & 1.579 & 1.481 & 1.404 & 1.312 & 1.580 & 1.482 & 1.359 & 1.312 & 1.565 & 1.499 & 1.394 & 1.301 \\
\hline & $c$ & 25.998 & 26.004 & 26.000 & 25.997 & 25.999 & 26.001 & 25.997 & 25.999 & 25.996 & 26.004 & 26.001 & 25.994 \\
\hline & $R_{\text {adj }}^{2}$ & 0.999 & 0.999 & 0.999 & 0.999 & 0.999 & 0.999 & 0.999 & 0.999 & 0.999 & 0.999 & 0.999 & 0.999 \\
\hline & $\operatorname{MRE}(\%)$ & 0.015 & 0.012 & 0.014 & 0.015 & 0.015 & 0.012 & 0.020 & 0.013 & 0.020 & 0.014 & 0.016 & 0.016 \\
\hline \multirow[t]{4}{*}{240} & $d T / d t\left(\times 10^{-2}\right)$ & 1.714 & 1.627 & 1.587 & 1.448 & 1.716 & 1.608 & 1.536 & 1.450 & 1.677 & 1.648 & 1.532 & 1.418 \\
\hline & $c$ & 26.000 & 26.002 & 26.009 & 25.999 & 25.997 & 25.994 & 26.002 & 25.996 & 25.993 & 26.007 & 26.000 & 25.991 \\
\hline & $R_{\text {adj }}^{2}$ & 0.999 & 0.999 & 0.999 & 0.999 & 0.999 & 0.999 & 0.999 & 0.999 & 0.999 & 0.999 & 0.999 & 0.999 \\
\hline & $\operatorname{MRE}(\%)$ & 0.014 & 0.013 & 0.023 & 0.018 & 0.014 & 0.010 & 0.015 & 0.019 & 0.029 & 0.020 & 0.011 & 0.028 \\
\hline \multirow[t]{4}{*}{280} & $d T / d t\left(\times 10^{-2}\right)$ & 1.828 & 1.769 & 1.658 & 1.566 & 1.858 & 1.725 & 1.659 & 1.592 & 1.858 & 1.784 & 1.670 & 1.591 \\
\hline & $c$ & 25.995 & 26.002 & 26.000 & 25.996 & 26.001 & 25.998 & 25.998 & 25.999 & 25.998 & 25.999 & 26.002 & 25.998 \\
\hline & $R_{\text {adj }}^{2}$ & 0.999 & 0.999 & 0.999 & 0.999 & 0.999 & 0.999 & 0.999 & 0.999 & 0.999 & 0.999 & 0.999 & 0.999 \\
\hline & $\operatorname{MRE}(\%)$ & 0.017 & 0.013 & 0.015 & 0.017 & 0.018 & 0.020 & 0.014 & 0.015 & 0.017 & 0.014 & 0.014 & 0.014 \\
\hline \multirow[t]{4}{*}{320} & $d T / d t\left(\times 10^{-2}\right)$ & 1.982 & 1.918 & 1.806 & 1.717 & 2.025 & 1.870 & 1.833 & 1.756 & 2.003 & 1.929 & 1.822 & 1.734 \\
\hline & $c$ & 25.996 & 26.002 & 26.000 & 25.997 & 26.002 & 25.995 & 26.002 & 26.002 & 25.996 & 25.999 & 26.005 & 25.996 \\
\hline & $R_{\text {adj }}^{2}$ & 0.999 & 0.999 & 0.999 & 0.999 & 0.999 & 0.999 & 0.999 & 0.999 & 0.999 & 0.999 & 0.999 & 0.999 \\
\hline & $\operatorname{MRE}(\%)$ & 0.014 & 0.013 & 0.013 & 0.017 & 0.015 & 0.019 & 0.014 & 0.018 & 0.008 & 0.015 & 0.015 & 0.015 \\
\hline
\end{tabular}

$U$ nominal input power (W), $x$ biomass concentration $\left(\mathrm{g} \mathrm{mL}^{-1}\right), d T / d t$ rate of experimental temperature $\left({ }^{\circ} \mathrm{C} \mathrm{s}^{-1}\right), c$ initial temperature of experimentation or the intercept of the graph $\left({ }^{\circ} \mathrm{C}\right)$

results of the fit model and their statistical validation are shown in Table 1. Equation (5) shows the simplified model of $\rho$ from Table 1. The fitted model obtained for $\rho$ shows the first- and second-order terms for the biomass concentration $\left(x, \mathrm{~g} \mathrm{~mL}^{-1}\right)$, temperature $\left(\mathrm{T},{ }^{\circ} \mathrm{C}\right)$, and $\mathrm{pH}$. The temperature factor was more significant, followed by the biomass concentration and the $\mathrm{pH}$.

The accuracy of the model was high according to the statistical parameter $R^{2}$ adj $>0.997$, which is a good adjustment for $\rho$ compared with the results obtained for agro-wastes, such as switchgrass, wheat straw, and corn stover (presenting $R^{2}$ values below 0.930) [49]. The residual analyses between the experimental and calculated data of $\rho$ by the fitted model (Eq. (5)) are shown in Fig. 3.

$$
\begin{aligned}
\rho= & 1001.2+465.7 x-0.929 \mathrm{pH}-3.774 \\
& \times 10^{-3} \mathrm{~T}^{2}-34.364 x \cdot \mathrm{pH}+3.759 x \cdot \mathrm{pH}^{2}
\end{aligned}
$$

The densities of the aqueous solutions containing the banana flower stalks are important when designing devices for the industry and in the control of the process. Moreover, the effects of density during the ultrasonic process are evident (e.g., in the calculation of the attenuation coefficient [40] and the mass described in Eq. (1) by the gravimetric method $[24,26]$ when the system contains biomass with different morphologies that occupy the same volume).

\subsection{Specific heat capacity correlation, $c_{p}$}

In this work, a $c_{p}$ model from the experimental results published by Villa-Vélez et al. [41] was used as a function of the biomass concentration, $\mathrm{pH}$, and temperature. The model represented by Eq. (6) resulted in a good, simple description of the experimental data under all of the conditions studied $\left(R^{2}\right.$ adj $>0.998$ and MRE <0.141\%) and only involved first terms.

$c_{p}=4.161-4.161 x+2.164 \times 10^{-4} \mathrm{~T}+1.579 \times 10^{-3} \mathrm{pH}(6)$ 
Table 3 Acoustic fields of the aqueous solutions containing biomass as a function of the position ( $1 \mathrm{~cm}$ from the tip of sonotrode (model H40, Hielscher Ultrasonics $\mathrm{GmbH}$, Germany)), nominal power, ultrasonic intensity, biomass concentration, and $\mathrm{pH}$

\begin{tabular}{|c|c|c|c|c|c|c|c|}
\hline \multirow[t]{2}{*}{$U$} & \multirow[t]{2}{*}{$x$} & \multicolumn{3}{|l|}{$P$} & \multicolumn{3}{|l|}{$I$} \\
\hline & & $\mathrm{pH}=3$ & $\mathrm{pH}=5$ & $\mathrm{pH}=7$ & $\mathrm{pH}=3$ & $\mathrm{pH}=5$ & $\mathrm{pH}=7$ \\
\hline \multirow[t]{4}{*}{120} & 0.040 & 97 & 94 & 95 & 37 & 36 & 37 \\
\hline & 0.060 & 86 & 86 & 86 & 33 & 33 & 33 \\
\hline & 0.080 & 77 & 79 & 78 & 30 & 31 & 30 \\
\hline & 0.100 & 73 & 72 & 72 & 28 & 28 & 28 \\
\hline \multirow[t]{4}{*}{160} & 0.040 & 104 & 104 & 102 & 40 & 40 & 39 \\
\hline & 0.060 & 96 & 98 & 95 & 37 & 38 & 37 \\
\hline & 0.080 & 87 & 89 & 88 & 34 & 34 & 34 \\
\hline & 0.100 & 81 & 81 & 80 & 31 & 31 & 31 \\
\hline \multirow[t]{4}{*}{200} & 0.040 & 115 & 115 & 114 & 44 & 44 & 44 \\
\hline & 0.060 & 106 & 107 & 108 & 41 & 41 & 41 \\
\hline & 0.080 & 100 & 96 & 99 & 38 & 37 & 38 \\
\hline & 0.100 & 92 & 92 & 91 & 35 & 35 & 35 \\
\hline \multirow[t]{4}{*}{240} & 0.040 & 125 & 125 & 122 & 48 & 48 & 47 \\
\hline & 0.060 & 117 & 116 & 118 & 45 & 45 & 46 \\
\hline & 0.080 & 113 & 109 & 109 & 43 & 42 & 42 \\
\hline & 0.100 & 101 & 101 & 99 & 39 & 39 & 38 \\
\hline \multirow[t]{4}{*}{280} & 0.040 & 133 & 135 & 135 & 51 & 52 & 52 \\
\hline & 0.060 & 127 & 124 & 128 & 49 & 48 & 49 \\
\hline & 0.080 & 118 & 118 & 118 & 45 & 45 & 46 \\
\hline & 0.100 & 109 & 111 & 111 & 42 & 43 & 43 \\
\hline \multirow[t]{4}{*}{320} & 0.040 & 144 & 147 & 146 & 56 & 57 & 56 \\
\hline & 0.060 & 138 & 134 & 138 & 53 & 52 & 53 \\
\hline & 0.080 & 128 & 130 & 129 & 49 & 50 & 50 \\
\hline & 0.100 & 120 & 123 & 121 & 46 & 47 & 47 \\
\hline
\end{tabular}

$U$ nominal input power (W), $P$ energy of power ultrasound transmitted in the aqueous solutions of biomass (W), I acoustic intensity transmitted in the aqueous solution of biomass $\left(\mathrm{W} \mathrm{cm}^{-2}\right), x$ biomass concentration $\left(\mathrm{g} \mathrm{mL}^{-1}\right)$

\subsection{Acoustic fields in the aqueous solutions containing biomass}

The relationship between the temperature and the time of ultrasound application was linear for all of the nominal input powers that were tested. Figure 4 shows such a relationship for 120 to $320 \mathrm{~W}$. The temporal temperature variations decreased as the biomass concentrations decreased for all levels of $\mathrm{pH}$ and power ultrasound $(\mathrm{U}, \mathrm{W})$. In contrast, the temporal temperature variations increased as the power ultrasound increased at each biomass concentration and $\mathrm{pH}$ level. According to Mason et al. [34], cavitation is the main cause of temperature increases, followed by pressure, viscosity, and the surface tension of the solution. Moreover, a change in these properties with time is considered normal, which allows for anticipated change in the acoustic properties of the medium, which depends on the geometry of the vessel and on the position of the probe tip.

Thus, the experimental data shown in Fig. 4 can be fit using Eq. (7) and by using the nlinfit Matlab function with a nonlinear regression.

$\mathrm{T}=\frac{d T}{d t} t+c$

In Eq. (7), $T$ is the temperature and $c$ is the intercept, which corresponds to the initial experimental temperature $\left({ }^{\circ} \mathrm{C}\right)$.

From Table 2, the accuracy of the regression is good, with $R^{2}$ adj $\geq 0.999$ and MRE $<0.032 \%$. The gradient of temperature $d T / d t$ ranged from $1.026 \times 10^{-2}$ to $2.025 \times 10^{-2}{ }^{\circ} \mathrm{C} \mathrm{s}^{-1}$, and the intercept $c$ was similar to the initial experimental temperature $\left(\approx 26{ }^{\circ} \mathrm{C}\right)$. Furthermore, $d T / d t$ was similar at $\mathrm{pH}$ values of 3,5 , and 7 , with a lower significance for this factor.

Once the $d T / d t$ and the correlated models for $\rho$ (Eq. (5)) and $c_{p}$ (Eq. (6)) were obtained, the energy, the power ultrasound $(P)$, and the acoustic intensity $(I)$ that was transmitted to the aqueous solutions of biomass were calculated using Eqs. (1) and (2), respectively. For both acoustic properties, it was assumed that the area of the sound wave jet was proportional to the base of the sonotrode and the final measured position at $1.0 \mathrm{~cm}$ from the top. The results obtained for the acoustic fields in the aqueous solutions of biomass are shown in Table 3.

Table 3 shows a direct relationship between the nominal input power $(U)$, the energy of the power ultrasound $(P)$, and the acoustic intensity $(I)$ transferred to the aqueous solution of biomass. In addition, $P$ and $I$ both decrease when the biomass ultrasound increases at each level of $U$ and $\mathrm{pH}$. Furthermore, the power ultrasound and
Table 4 Fitting model results of the ultrasound energy of power and the intensity of the ultrasound transmitted through the aqueous solutions containing biomass according to the stepwise regression method

\begin{tabular}{clcccc}
\hline Acoustic property & Coefficient & Value & $p(<0.05)$ & $R_{\text {adj }}^{2}$ & MRE (\%) \\
\hline$P$ & Intercept & 79.728 & - & 0.995 & 0.949 \\
& $U$ & $25.157 \times 10^{-2}$ & $2.284 \times 10^{-79}$ & & \\
& $x$ & -390.840 & $2.431 \times 10^{-59}$ & & \\
& Intercept & 30.708 & - & 0.995 & 0.949 \\
& $U$ & $96.891 \times 10^{-3}$ & $2.276 \times 10^{-79}$ & & \\
& $x$ & -150.530 & $2.422 \times 10^{-59}$ & & \\
\hline
\end{tabular}

- not applied, $p$ probability of the factor $F(\alpha=95 \%), x$ biomass concentration $\left(\mathrm{g} \mathrm{mL}^{-1}\right), P$ energy of power ultrasound transmitted in the aqueous solutions containing biomass (W), $I$ acoustic intensity transmitted in the aqueous solutions of biomass $\left(\mathrm{W} \mathrm{cm}^{-2}\right), U$ nominal input power (W) 

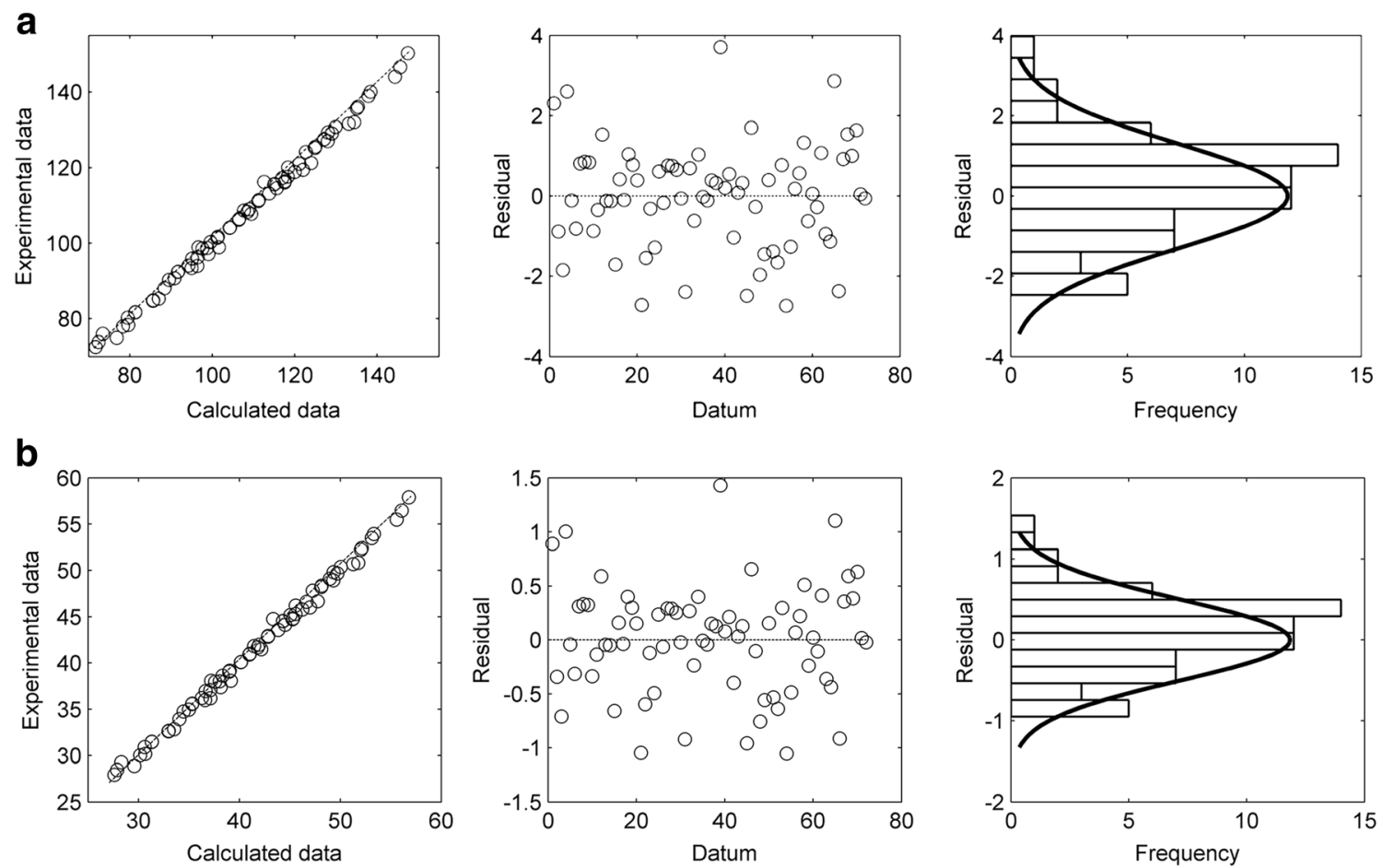

Fig. 5 Residual analysis between the experimental and calculated ultrasound energy of power (a) and acoustic intensity (b) transmitted in the aqueous solutions of biomass
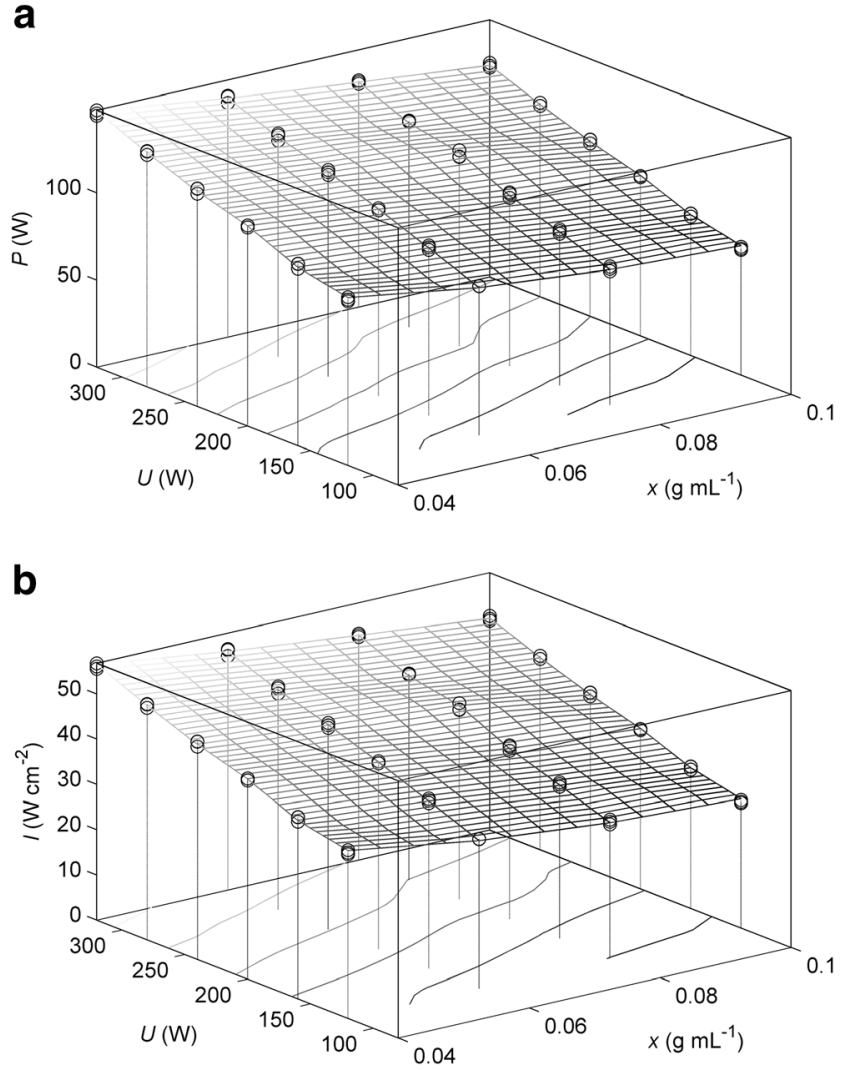

Fig. 6 Experimental data (circle) and calculated data (mesh (square)) of the ultrasound energy of power (a) and the acoustic intensity (b) transmitted in the aqueous solutions of biomass by the correlated models as a function of the biomass concentration $(x)$ and nominal power ultrasound $(\mathrm{W})$ the acoustic intensity transferred to the aqueous solutions of biomass showed a loss of energy of approximately $19 \%$ at $U=120 \mathrm{~W}$, and an increment of approximately $62 \%$ at $U=320 \mathrm{~W}$. This behavior was observed by Merouani et al. [16] and Brotchie et al. [42] and was attributed to the mean bubble size generated in the liquid. The bubble size is a characteristic of the applied acoustic frequency. When the bubble size is kept constant and the nominal input power varies, only the pressure of the jet is affected, which produces more or fewer bubbles. According to Hauptmann et al. [43], the cavitation activity is strongly linked to the movement of the bubbles, and these bubbles could be essential for propagating the cavitation activity in the chamber. Beginning at the regions near the sonotrode, these bubbles could move at velocities of more than an order of magnitude $\left(\mathrm{m} \mathrm{s}^{-1}\right)$ in the direction of the acoustic field propagation. This fast movement indicates strong oscillatory activity due to the translational movement of the acoustic radiation forces, which are characteristic of wave fields.

With the results obtained from the acoustic fields in the aqueous biomass solutions (Table 3), a model for the acoustic properties $P(\mathrm{~W})$ and $\left.I(\mathrm{~W} \mathrm{~cm})^{-2}\right)$ as a function of the nominal input power, biomass concentration, $\mathrm{pH}$, and position of $1 \mathrm{~cm}$ from the sonotrode was obtained using the stepwise regression method. The model regression results for both properties and their statistical validation are shown in Table 4 . The residual analyses of the 
calculated acoustic properties by the fitting models are shown in Fig. 5.

Table 4 shows two models (simplified in Eqs. (8) and (9)) with the same parameters for $P(\mathrm{~W})$ and $I\left(\mathrm{~W} \mathrm{~cm}^{-2}\right)$. In these models, the biomass concentration $\left(x, \mathrm{~g} \mathrm{~mL}^{-1}\right)$ and nominal input power $(U, \mathrm{~W})$ influenced the values of these properties ( $\mathrm{pH}$ has not influenced). The results of MRE $<0.949$ showed a close relationship between the experimental and modeled values, which is indicated graphically in Fig. 6.

$P=79.728+25.157 \times 10^{-2} U-390.840 x$

$I=30.708+96.891 \times 10^{-3} U-150.530 x$

Equations (8) and (9) are simple models that describe the behavior of the acoustic fields in aqueous solutions of biomass when applied to a different nominal power ultrasound at a frequency of $24 \mathrm{kHz}$. Although these results provide significant information regarding the acoustic fields in a local position, the procedures involved in this research can be adapted and applied to identify $P$ and $I$ for different positions from the sonotrode because the calorimetric method is the most suitable for this material. The acoustic field could be predicted by acoustic mapping [29] or by numerical simulation [28, 44], and can be used to understand acoustic phenomenon in biomass. Finally, with the high concentration of biomass in the solution, the dissipation of the nominal power ultrasound was higher, which could result in large economic losses at the industrial level if applied. Thus, studies regarding the geometry of the acoustic system and the capacity of ultrasound processing of aqueous biomass solutions at a large scale are suggested for future studies.

\section{Conclusions}

Based on the results of the research, was concluded the following:

It is observed that the calorimetric method is appropriate to determine the acoustic fields in lignocellulose biomass pretreated with power ultrasound equipment. However, the calorimetric method is complicated to apply for long time of sonication at a low cavitation activity when there is no acoustic streaming to ensure homogenous temperature distribution in the loading medium. In addition, the use of experimental procedures for determining the specific heat capacity and density was essential for obtaining more accuracy when calculating the acoustic fields.

The use of acidified aqueous solutions containing banana flower stalk at several conditions of concentrations and $\mathrm{pH}$ shows an important trend about studies of pretreatment methods to obtain fermentable sugars without material costs for the bioenergy industry. In this case, the acidification of the water ( $\mathrm{pH} 3$ to 7) helps for further stages of pretreatments (e.g., enzymatic hydrolyses) and does not represent any costs with effluent treatments.

Finally, the use of computational methodologies as a finite element method is suggested for future studies to determine the acoustic fields at different positions of the sonotrode to model the sound wave propagation, which is important for the design and construction of acoustic processor systems.

Acknowledgments The authors are grateful for the financial support received from the Coordination for the Improvement of Higher Education Personnel (CAPES) and the São Paulo Research Foundation (FAPESP, Prot. No.: 2013/17497-5) for this doctoral project.

\section{References}

1. Langan P, Gnanakaran S, Rector KD, Pawley N, Fox DT, Cho DW et al (2011) Exploring new strategies for cellulosic biofuels production. Energy Environment Sci 4:3820-3833

2. Velásquez-Arredondo HI, de Oliveira JS, Benjumea P (2012) Exergy efficiency analysis of chemical and biochemical stages involved in liquid biofuels production processes. Energy 41:138-145

3. Hoogwijk M, Faaij A, van de Broek R, Berndes G, Gielen D, Turkenburg W (2003) Exploration of the ranges of the global potential of biomass for energy. Biomass Bioenergy 25:119-133

4. Villa-Vélez HA, Váquiro HA, Telis-Romero J (2015) The effect of power-ultrasound on the pretreatment of acidified aqueous solutions of banana flower-stalk: structural, chemical and statistical analysis. Ind Crop Prod 66:52-61

5. Hammond JB, Egg R, Diggins D, Coble CG (1996) Alcohol from bananas. Bioresour Technol 56:125-130

6. Tock JY, Lai CL, Lee KT, Tan KT, Bhatia S (2010) Banana biomass as potential renewable energy resource: a Malaysian case study. Renew Sust Energ Rev 14:798-805

7. Olsen C, Arantes V, Saddler J (2012) The use of predictive models to optimize sugar recovery obtained after the steam pre-treatment of softwoods. Biofuels Bioprod Biorefin 6:534-548

8. Xiong Q, Kong S-C, Passalacqua A (2013) Development of a generalized numerical framework for simulating biomass fast pyrolysis in fluidized-bed reactors. Chem Eng Sci 99:305-313

9. Xiong Q, Aramideh S, Kong S-C (2013) Modeling effects of operating conditions on biomass fast pyrolysis in bubbling fluidized bed reactors. Energy Fuel 27:5948-5956

10. Kumar P, Barret DM, Delwiche MJ, Stroeve P (2011) Pulsed electric field pretreatment of switchgrass and wood chip species for biofuel production. Ind Eng Chem Res 50:10996-11001

11. Luo J, Fang Z, Smith RL (2014) Ultrasound-enhanced conversion of biomass to biofuels. Prog Energ Combust Sci 41:56-93

12. Sawant SS, Anil AC, Krishnamurthy V, Gaonkar C, Kolwalkar J, Khandeparker L et al (2008) Effect of hydrodynamic cavitation on zooplankton: a tool for disinfection. Biochem Eng J 42:320-328

13. Pinjari DV, Pandit AB (2010) Cavitation milling of natural cellulose to nanofibrils. Ultrason Sonochem 17:845-852

14. Berlan J, Mason TJ (1992) Sonochemistry: from research laboratories to industrial plants. Ultrasonics 30:203-212 
15. Cárcel JA, Benedito J, Mulet A (2012) Food process innovation through new technologies: use of ultrasound. J Food Eng 110:200207

16. Merouani S, Hamdaoui O, Rezgui Y, Guemini M (2014) Energy analysis during bubble oscillations: relationship between bubble energy and sonochemical parameters. Ultrasonics 54:227-232

17. Sasmal S, Goud VV, Mohanty K (2012) Ultrasound assisted lime pretreatment of lignocellulosic biomass toward bioethanol production. Energy Fuel 26:3777-3784

18. Park ND, Helle SS, Thring RW (2012) Combined alkaline and ultrasound pre-treatment of thickened pulp mill waste activated sludge for improved anaerobic digestion. Biomass Bioenergy 46: 750-756

19. Khanel SK, Montabo M, Leeuwen J, Srinivasan G, Grewell D (2007) Ultrasound enhanced glucose release from corn in ethanol plants. Biotechnol Bioeng 98:978-985

20. Jiang J, Zhao Q, Wei L, Wang K, Lee D-J (2011) Degradation and characteristic changes of organic matter in sewage sludge, using microbial fuel cell with ultrasound pretreatment. Bioresour Technol 102:272-277

21. Esfahani MR, Azin M (2012) Pretreatment of sugar cane bagasse by ultrasound energy and dilute acid. Asia Pac J Chem Eng 7:274278

22. Rokhina EV, Repo E, Virkutyte J (2010) Comparative kinetic analysis of silent and ultrasound-assisted catalytic wet peroxide oxidation of phenol. Ultrason Sonochem 17:541-546

23. Yunus R, Salleh SF, Abdullah N, Biak DRA (2010) Effect of ultrasonic pre-treatment on low temperature acid hydrolysis of oil palm empty fruit bunch. Bioresour Technol 101:9792-9796

24. Raso J, Mañas P, Pagán R, Sala FJ (1999) Influence of different factors on the output power transferred medium by ultrasound. Ultrason Sonochem 5:157-162

25. Xiong Q, Xu F, Ramirez E, Pannala S, Daw CS (2016) Modeling the impact of bubbling bed hydrodynamics on tar yield and its fluctuations during biomass fast pyrolysis. Fuel 164:11-17

26. Toma M, Fukutomi S, Asakura Y, Koda S (2011) A calorimetric study of energy conversion efficiency of a sonochemical reactor at $500 \mathrm{kHz}$ for organic solvents. Ultrason Sonochem 18:197-208

27. Hu Y, Zhang Z, Yang C (2008) Measurement of hydroxyl radical production in ultrasonics aqueous solutions by a novel chemiluminescence method. Ultrason Sonochem 15:665-672

28. Lin S, Xu L (2012) Study on the radial vibration and acoustic field of an isotropic circular ring radiator. Ultrasonics 52:103-110

29. Moholkar VS, Sable SP, Pandit AB (2000) Mapping the cavitation intensity in an ultrasonic bath using the acoustic emission. AICHE J 46:684-695

30. Kumar A, Gogate PR, Pandit AB (2007) Mapping the efficacy of new designs for large scale sonochemical reactors. Ultrason Sonochem 14:538-544
31. Margulis MA, Maximenko NA (1991) The influence of ultrasound on oscilating reactions. Appendix: measurement of ultrasound absorbed power (calorimetric method). In: Mason TJ (ed) Advances in sonochemistry, 2nd edn. JAI Press Inc, London, pp $1-328$

32. Koda S, Kimura T, Kondo T, Mitone H (2003) A standard method to calibrate sonochemical efficiency of an individual reaction system. Ultrason Sonochem 10:149-156

33. AOAC (1997) Official methods of analysis international. Association of Offical Analytical Chemists International, Gaithersburg

34. Mason TJ, Lorimer JP, Bates DM (1992) Quantifying sonochemistry: casting some light on a "black art". Ultrasonics 30:40-42

35. Cevik A (2007) Unified formulation for web crippling strength of cold-formed steel sheeting using stepwise regression. J Constr Steel Res 63:1305-1316

36. Goodenough AE, Hart AG, Stafford R (2012) Regression with empirical variable selection: description of a new method and application to ecological datasets. PLoS One 7:1-10

37. Chen Y, Shi R, Shu S, Gao W (2013) Ensemble and enhanced $\mathrm{PM}_{10}$ concentration forecast model based on stepwise regression and wavelet analysis. Atmos Environ 74:346-359

38. Castell-Palou A, Váquiro HA, Cárcel JA, Rosselló C, Femenia A, Simal S (2012) Mathematical modeling of moisture distribution and kinetics in cheese drying. Dry Technol 30:1247-1255

39. Korosi G, Kovats ES (1981) Density and surface tension of 83 organic liquids. J Chem Eng Data 26:323-332

40. Petošic A, Svilar D, Ivancevic B (2011) Comparison of measured acoustic power results gained by using three different methods on an ultrasonic low-frequency device. Ultrason Sonochemistry 18: $567-576$

41. Villa-Vélez HA, Váquiro HA, Lopes-Filho JF, Telis VRN, TelisRomero J (2015) Study of the specific heat capacity of biomass from banana waste for application in the second-generation ethanol industry. Environ Prog Sustain Energy 34:1221-1228

42. Brotchie F, Grieser F, Ashokkumar M (2009) Effect of power and frequency on bubble-size distributions in acoustic cavitation. Phys Rev Let 102:084302-084301-084302-084304

43. Hauptmann M, Struyf H, Mertens P, Heyns M, De Gendt S, Glorieux C et al (2013) Towards an understanding and control of cavitation activity in $1 \mathrm{MHz}$ ultrasound fileds. Ultrason Sonochemistry 20:77-88

44. Pantea C, Osterhoudt CF, Sinha DN (2013) Determination of acoustical nonlinear parameter $\beta$ of water using the finite amplitude method. Ultrasonics 53:1012-1019 